\title{
Ruth A. Kleinerman \\ Cancer risks following diagnostic and therapeutic radiation exposure in children
}

\begin{abstract}
The growing use of interventional and fluoroscopic imaging in children represents a tremendous benefit for the diagnosis and treatment of benign conditions. Along with the increasing use and complexity of these procedures comes concern about the cancer risk associated with ionizing radiation exposure to children. Children are considerably more sensitive to the carcinogenic effects of ionizing radiation than adults, and children have a longer life expectancy in which to express risk. Numerous epidemiologic cohort studies of childhood exposure to radiation for treatment of benign diseases have demonstrated radiation-related risks of cancer of the thyroid, breast, brain and skin, as well as leukemia. Many fewer studies have evaluated cancer risk following diagnostic radiation exposure in children. Although radiation dose for a single procedure might be low, pediatric patients often receive repeated examinations over time to evaluate their conditions, which could result in relatively high cumulative doses. Several cohort studies of girls and young women subjected to multiple diagnostic radiation exposures have been informative about increased mortality from breast cancer with increasing radiation dose, and case-control studies of childhood leukemia and postnatal diagnostic radiation exposure have suggested increased risks with an increasing number of examinations. Only two long-term follow-up studies of cancer following cardiac catheterization in childhood have been conducted, and neither reported an overall increased risk of cancer. Most cancers
\end{abstract}

This research was supported by the Intramural Research Program of the National Institutes of Health, National Cancer Institute, Division of Cancer Epidemiology and Genetics.

R. A. Kleinerman $(\bowtie)$

Radiation Epidemiology Branch, Division of Cancer

Epidemiology and Genetics, National Cancer Institute,

National Institutes of Health, DHHS,

EPS 7044, 6120 Executive Blvd.,

Rockville, MD 20852, USA

e-mail: kleinerr@mail.nih.gov

Tel: $+1-301-5947166$

Fax: +1-301-4020207 can be induced by radiation, and a linear dose-response has been noted for most solid cancers. Risks of radiationrelated cancer are greatest for those exposed early in life, and these risks appear to persist throughout life.

Keywords Radiation risks - Carcinogenesis - Diagnostic radiation - Therapeutic radiation

\section{Introduction}

The growing use of interventional and fluoroscopic imaging in children represents a tremendous benefit for the diagnosis and treatment of benign conditions. Along with the increasing use and complexity of these procedures comes concern about the late effects of increased ionizing radiation exposure to children. Although radiation dose for a single procedure might be low, pediatric patients often receive repeated examinations over time to evaluate their conditions, which could result in relatively high cumulative doses. Most important, children are considerably more sensitive to the carcinogenic effects of ionizing radiation than adults, and children have a longer life expectancy resulting in a larger window of opportunity for expressing radiation damage. In addition to the studies of Japanese atomic bomb survivors, which have provided a wealth of data about radiation-related cancer risks, numerous epidemiologic studies of childhood exposure to radiation (X-rays and gamma rays) for treatment of benign diseases have demonstrated increased cancer risks with increasing radiation dose [1-3]. These studies have been extensively reviewed recently in the BEIR VII report "Health Risks from Exposure to Low Levels of Ionizing Radiation" [3], which concluded that the "available biological and biophysical data supports a 'linear-no-threshold' (LNT) risk model - that the risk of cancer proceeds in a linear fashion at lower doses without a threshold and that the smallest dose has the potential to cause a small increase in risk to humans." This paper highlights the major studies of cancer risk following childhood irradiation for treatment of benign disease and postnatal diagnostic radiation exposure. 


\section{Characteristics of epidemiologic studies of radiation exposure}

Many of the classic epidemiologic studies of cancer following medical radiation exposure are distinguished by a cohort design, large population size, long-term followup of the cohort, well-characterized dose estimates for individuals, and a wide range of doses in order to estimate a dose-response relationship. Studies based on a cohort design are generally less likely to be biased than casecontrol studies that depend on the retrospective collection of data. Large population size is usually required to evaluate the risk of cancer, because cancer is a rare outcome, especially in children. In addition, the lower the radiation dose, the larger the population size required to detect a radiation effect [4]. Although radiation-induced leukemia generally occurs within 3 to 5 years of radiation exposure, solid tumors usually start to be diagnosed a minimum of 10 to 15 years after exposure and often do not appear until the child has reached adulthood [1]. Therefore, study subjects, especially children, usually need to be monitored for many years for solid cancer development.

Radiation-related cancer risk is typically expressed as excess relative risk (ERR) or excess absolute risk (EAR), which facilitates comparison across studies. Both of these measures of radiation risk represent increased cancer rates relative to an unexposed population, on a relative scale (ERR) or an absolute scale (EAR). For example, an ERR of 1 corresponds to a doubling of the cancer rate in the exposed population compared to the unexposed population, whereas an EAR represents the additional number of cancers in the exposed population compared to the number of cancers in the unexposed population.

Several factors might modify the risk of cancer following radiation exposure. These factors include: gender (e.g., females are more sensitive than males to the carcinogenic effects of radiation to the thyroid); age at exposure (younger children are more susceptible to radiation effects than older children); attained age (cancer might not appear until the child has reached adulthood, when cancers typically occur); time since exposure (solid tumors start to appear 10 15 years after exposure); underlying disease (disease requiring radiation treatment might predispose to cancer); and other potential carcinogens (cigarette smoking might interact with radiation exposure).

\section{Studies of children irradiated for benign diseases}

Studies of pediatric patients irradiated for benign diseases avoid possible confounding by the presence of existing malignant disease, and these patients generally receive lower doses of radiation than children being treated for cancer. Detailed radiotherapy records usually exist to permit quantification of the radiation dose received by the child. Treatments are usually partial-body, and doses might be fractionated or protracted, depending on the treatment schedule, and non-irradiated patients are often available for comparison.

The most radiosensitive organ sites in children in order of sensitivity are the thyroid gland, breasts, bone marrow (leukemia), brain and skin [1]. The evidence for increased radiation-related risk for these cancers following childhood therapeutic radiation has come from long-term cohort studies of infants irradiated for suspected enlarged thymus glands or hemangiomas of the face and neck, and young children irradiated for tinea capitis of the scalp or for enlarged tonsils (Table 1).

Table 1 Cancer risks following childhood therapeutic irradiation for benign diseases

\begin{tabular}{|c|c|c|c|c|c|}
\hline Cancer site & Benign condition, cohort & No. of irradiated subjects & Mean age (years) & Mean dose (Gy) & ERR/Gy $(95 \%$ CI $)$ \\
\hline \multirow{3}{*}{ Thyroid } & Tinea capitis, New York & 2,224 & 7.8 & 0.1 & $7.7(<0-60)$ \\
\hline & Hemangioma $^{\mathrm{a}}$, Stockholm & 14,435 & $<1.5$ & 0.3 & $4.9(1.3-10)$ \\
\hline & Enlarged tonsils, Chicago & 2,634 & 4 & 0.6 & $2.5(0.6-26)$ \\
\hline Breast & Thymus, Rochester, NY & 1,201 & $<1$ & 0.7 & $2.5(1.1-5.2)$ \\
\hline \multirow[t]{2}{*}{ Leukemia } & Tinea capitis, Israel & 10,834 & 7.1 & 0.3 & Not available \\
\hline & Hemangioma (pooled) $^{\mathrm{a}}$ & 28,008 & 0.5 & 0.1 & $1.6(-0.6-5.5)$ \\
\hline \multirow[t]{2}{*}{ Brain } & Tinea capitis, Israel & 10,834 & 7.1 & 1.5 & $4.6(2.4-9.1)^{\mathrm{b}}$ \\
\hline & & & & 1.5 & $2.0(0.7-4.7)^{\mathrm{c}}$ \\
\hline
\end{tabular}

\footnotetext{
${ }^{a}$ Radium-226 treatment

${ }^{b}$ Benign tumor only

${ }^{\mathrm{c}}$ Malignant tumor only

${ }^{\mathrm{d} B e n i g n}$ and malignant tumors combined
} 


\section{Thyroid cancer}

Although thyroid cancer is rare, six large cohort studies of childhood irradiation have demonstrated a radiation-related risk for thyroid cancer. Children were irradiated for either tinea capitis of the scalp $[5,6]$, suspected enlarged thymus glands [7], enlarged tonsils [8], or a hemangioma on the face or neck $[9,10]$. Mean doses to the thyroid ranged from $0.1 \mathrm{~Gy}$ for tinea capitis to $1.4 \mathrm{~Gy}$ for thymic irradiation. The highest ERR per Gray followed radiation for tinea capitis and the lowest ERR was noted following tonsil irradiation. In addition to these studies, Ron et al. [11] pooled data from studies of radiation-related thyroid cancer in children and adults that included 58,000 individuals exposed to external radiation and 61,000 non-exposed individuals. Among children younger than age 15 years at exposure, Ron et al. noted a linear dose-response down to 0.1 Gy, and the ERR/Gy was 7.7 (95\% CI, 2.1-28.7). The corresponding EAR/10 $4 \mathrm{PY} / \mathrm{Gy}$ for childhood exposure was 4.4 (95\% CI 1.9, 10.1). These studies demonstrated that the thyroid gland is very sensitive to the carcinogenic effects of radiation, characterized by a strong linear doseresponse down to $0.1 \mathrm{~Gy}$. Risk for radiation-related thyroid cancer decreased with increasing age at exposure and persisted over time up to 30 years after radiation exposure. Thyroid cancer risk was three times higher in females than in males, similar to the background rates in the general population.

\section{Breast cancer}

The studies of radiation treatment for enlarged thymus gland [12] and hemangioma [13] have provided data on radiation-related risk of breast cancer. The doses to the breast ranged 20 -fold in these studies, from 0.1 to $2.1 \mathrm{~Gy}$. Overall, the risk of breast cancer increased linearly with increasing dose to the breast; risk decreased with increasing age at exposure; and risk persisted up to 50 years after exposure to radiation. In a pooled analysis of radiation effects on breast cancer risk, Preston et al. [14] concluded that the excess risk of breast cancer in the hemangioma cohorts was about one-seventh of the risk in the thymic cohort, likely due to low-dose-rate protracted exposures from Ra-226 in the hemangioma cohorts compared to the high-dose-rate exposures in the thymic cohort [14].

\section{Leukemia}

Mortality from leukemia was evaluated in the Israeli tinea capitis [15] and the Swedish hemangioma [16] cohorts. In the Israeli tinea study, the EAR $/ 10^{4} / \mathrm{Gy}$ was 0.9 , based on a mean average bone marrow dose of $0.3 \mathrm{~Gy}$. No significant association between dose (average bone marrow dose 0.1 , $<0.01$ to $4.6 \mathrm{~Gy}$ ) and leukemia was detected in the hemangioma cohort. Among those irradiated subjects in the hemangioma cohort who received more than $0.1 \mathrm{~Gy}$, investigators estimated the ERR/Gy separately for leukemia deaths occurring in childhood $(5.0,95 \%$ CI $0.1-15)$ and in adulthood $(-0.02,95 \% \mathrm{CI}-0.08-1.9)$. The combined ERR/ Gy was $1.6(95 \% \mathrm{CI}-0.6-5.5)$.

\section{Brain tumors}

Brain tumors, both malignant and benign, have been reported following radiotherapy for tinea capitis $[17,18]$ and hemangioma [19] following doses on the order of 12 Gy. In the Israeli tinea study, the dose to the brain was 1.5 Gy (range 1-6 Gy), and the ERR/Gy was higher for benign meningiomas than for malignant tumors $(4.6,95 \%$ CI 2.4-9.1 vs. $1.98,95 \%$ CI $0.7-4.7)$ after a median of 40 years of follow-up of the cohort. However, the ERR/Gy decreased with increasing age at exposure for malignant but not for benign tumors. Among the hemangioma cohort, the mean absorbed intracranial dose was lower (0.07 Gy), but had a wider range $(<0.01-11.5 \mathrm{~Gy})$. The ERR was $2.7 /$ Gy (95\% CI 1.0-5.6) for malignant and benign tumors combined, and the ERR decreased with increasing age at exposure. Both of these studies noted a strong doseresponse, a decreasing risk of brain tumors with increasing age at exposure, and an elevated risk 30 and more years after exposure.

\section{Non-melanoma skin cancer}

Skin cancer on the scalp and face was evaluated following radiotherapy for tinea capitis in both the New York [20] and the Israeli series [21]. Doses ranged from $3 \mathrm{~Gy}$ to $6 \mathrm{~Gy}$ to the scalp. In both studies, significantly increased risks for skin cancer were noted for basal cell cancers only, and these cancers appeared after a minimum latency of 20 years. The excess relative risks were higher for New York; the ERR/Gy was 0.7 (95\% CI 0.3-1.4) for the Israeli series and the ERR/Gy was 1.6 (95\% CI 1.3-2.1) for the New York series. An interaction of ionizing radiation with ultraviolet radiation was suggested by a preponderance of skin cancers in sun-exposed areas and very few of these cancers were diagnosed in blacks, who received the same exposures.

\section{Diagnostic radiation exposure in children}

Many fewer studies have evaluated the cancer risk following diagnostic radiation exposure in children (Table 2). Unless diagnostic procedures are performed multiple times, doses are typically low, and the sample sizes required to detect a risk of cancer are often impractically large. However, studies of radiation exposure from multiple chest fluoroscopies used to monitor treatment for tuberculosis (TB) in adolescent girls and young women [22-25], and a study of multiple diagnostic X-ray examinations to monitor curvature of the spine in girls with scoliosis [26] have reported increased mortality from breast cancer with increasing radiation dose. In the TB cohorts, 
Table 2 Cancer risk following diagnostic radiation exposure in childhood and adolescence (OR odds ratio)

\begin{tabular}{|c|c|c|c|c|c|c|}
\hline $\begin{array}{l}\text { Cancer } \\
\text { site }\end{array}$ & Underlying condition & $\begin{array}{l}\text { Cohort: study } \\
\text { size }\end{array}$ & $\begin{array}{l}\text { Mean age } \\
\text { (years) }\end{array}$ & $\begin{array}{l}\text { Dose } \\
\text { (Gy) }\end{array}$ & $\begin{array}{l}\text { No. of X-ray } \\
\text { examinations }\end{array}$ & Risk estimate \\
\hline \multirow[t]{4}{*}{ Breast } & \multirow[t]{3}{*}{ Tuberculosis } & USA: 1,494 & 15 & 0.8 & & ERR/Gy $0.4(0.2-0.7)$ \\
\hline & & Canada, Nova Scotia: 984 & 26 & 2.1 & & ERR/Gy 3.6 (1.8-6.8) \\
\hline & & Canada, other: 12,094 & 26 & 0.8 & & ERR/Gy $0.4(0.1-0.8)$ \\
\hline & Scoliosis & USA: 5,573 & 10.6 & 0.1 & & ERR/Gy $2.7(-0.2-9.3)$ \\
\hline \multirow[t]{5}{*}{ Leukemia } & \multirow{2}{*}{$\begin{array}{l}\text { Diagnostic X-ray } \\
\text { examinations of } \\
\text { broken bones }\end{array}$} & \multirow{2}{*}{$\begin{array}{l}\text { Canada: } 491 \text { patients } \\
\text { with acute lymphoblastic } \\
\text { leukemia, } 491 \text { controls }\end{array}$} & \multirow[t]{2}{*}{$<10$} & & 1 & OR 1.04 (95\% CI $0.7-1.5)$ \\
\hline & & & & & $\geq 2$ & OR $1.61(95 \%$ CI $1.1-2.3)$ \\
\hline & $\begin{array}{l}\text { Diagnostic X-ray } \\
\text { examinations }\end{array}$ & $\begin{array}{l}\text { China: } 166 \text { patients } \\
\text { with acute leukemia, } \\
166 \text { controls }\end{array}$ & $<15$ & & $\geq 1$ & OR $1.6(95 \%$ CI $1.0-2.6)$ \\
\hline & \multirow{2}{*}{$\begin{array}{l}\text { Diagnostic X-ray } \\
\text { examinations }\end{array}$} & \multirow{2}{*}{$\begin{array}{l}\text { US: } 1,842 \text { patients with } \\
\text { acute lymphoblastic } \\
\text { leukemia, } 1986 \text { controls }\end{array}$} & \multirow[t]{2}{*}{$<15$} & & $\leq 2$ & OR $0.9(95 \%$ CI $0.8-1.1)$ \\
\hline & & & & & $\geq 3$ & OR $1.2(95 \%$ CI 1.0-1.6) \\
\hline \multirow[t]{3}{*}{ All sites } & $\begin{array}{l}\text { Cardiac } \\
\text { catheterization }\end{array}$ & Israel: 674 & 8.9 & $0.05-0.4$ & & $\begin{array}{l}\text { OR } 2.0(95 \% \text { CI } 0.8-4.2) \text {, } \\
\text { one procedure } \\
\text { OR } 1.4(95 \% \text { CI } 0.4-3.5) \text {, } \\
\text { two procedures }\end{array}$ \\
\hline & \multirow[t]{2}{*}{$\begin{array}{l}\text { Cardiac } \\
\text { catheterization }\end{array}$} & \multirow[t]{2}{*}{ Canada: 3,915} & \multirow[t]{2}{*}{3.8} & \multirow[t]{2}{*}{$0.2-0.5$} & & $\begin{array}{l}\text { OR } 0.7(95 \% \text { CI } 0.4-1.3) \text {, } \\
\text { one procedure }\end{array}$ \\
\hline & & & & & & $\begin{array}{l}\text { OR } 0.8(95 \% \text { CI } 0.3-1.7) \text {, } \\
\text { two procedures }\end{array}$ \\
\hline
\end{tabular}

the average breast doses from highly fractionated highdose-rate exposures ranged from 0.79 to $2.1 \mathrm{~Gy}$, whereas in the scoliosis cohort, the average breast dose was lower, $0.11 \mathrm{~Gy}$. In these studies, the risk of breast cancer began to appear 15 years after radiation exposure and the risk remained elevated up to 50 years later. Based on the data from the young women exposed to multiple chest fluoroscopies during TB therapy, fractionation of the radiation dose may not have had a sparing effect on the excess breast cancer rates [14].

Two population-based case-control studies (China [27] and Canada [28]) and one institutionally based study in the US [29] of sufficient size have provided estimates of radiation-related leukemia following postnatal diagnostic X-ray examinations. A population-based study in Shanghai, China, reported a marginally elevated risk for acute leukemia associated with diagnostic X-ray examinations (odds ratio 1.6, 95\% CI 1.0-2.6) among 166 children with cancer compared with 166 controls. In a study of childhood acute lymphoblastic leukemia (ALL) in Quebec, the risk for ALL rose with increasing number of diagnostic X-ray examinations (mostly bone examinations) from OR 1.04 for one examination to OR 1.61 for two or more examinations, based on 491 patients and 491 controls. The institutionally based study in the US of 1,842 children with acute lymphoblastic leukemia and 1,986 controls reported a slightly decreased risk for one or two X-ray examinations (OR 0.9) and a modestly increased risk for three or more X-ray examinations (OR 1.2).
A study of 674 children in Israel (1950-1970) [30] measured cancer incidence, and a larger study of 3,915 children in Canada (1950-1965) [31, 32] evaluated cancer incidence and mortality following cardiac catheterization procedures. Individual dose estimates were not available, but skin doses likely ranged from 0.05 to 0.47 Gy during the time period of the study. Neither study reported an overall increased risk of cancer. In Israel, risk decreased with increasing number of procedures (OR 2.0 for one procedure, OR 1.4 for two procedures) and the cancers occurred in males only; in Canada, risks for cancer were less than expected (OR 0.7 for one procedure and OR 0.8 for two procedures).

\section{Conclusion}

Many studies of radiation for treatment of benign diseases and a few studies of diagnostic radiation exposure have yielded much of the information on the risk for radiationrelated cancer in children. Although most cancers can be induced by radiation, these studies demonstrate doserelated increased risks of cancer of the thyroid, breasts and brain, non-melanoma skin cancer, and leukemia. Risks were related to radiation dose and appeared to be greatest for children irradiated early in life, and risks for solid tumors persisted throughout life. 


\section{References}

1. UNSCEAR (2000) UNSCEAR 2000. The United Nations Scientific Committee on the Effects of Atomic Radiation. Health Phys 79:314

2. Ron E (2003) Cancer risks from medical radiation. Health Phys $85: 47-59$

3. National Academy of Sciences (2005) Health risks from exposure to low levels of ionizing radiation: BEIR VII. National Academies Press, Washington DC

4. Land CE (1980) Estimating cancer risks from low doses of ionizing radiation. Science 209:1197-1203

5. Ron E, Modan B, Preston D, et al (1989) Thyroid neoplasia following low-dose radiation in childhood. Radiat Res 120:516-531

6. Shore RE (1992) Issues and epidemiological evidence regarding radiation-induced thyroid cancer. Radiat Res 131:98-111

7. Shore RE, Hildreth N, Dvoretsky P, et al (1993) Thyroid cancer among persons given X-ray treatment in infancy for an enlarged thymus gland. Am J Epidemiol 137:1068-1080

8. Schneider AB, Ron E, Lubin J, et al (1993) Dose-response relationships for radiation-induced thyroid cancer and thyroid nodules: evidence for the prolonged effects of radiation on the thyroid. J Clin Endocrinol Metab 77:362-369

9. Lundell M, Hakulinen T, Holm LE (1994) Thyroid cancer after radiotherapy for skin hemangioma in infancy. Radiat Res 140:334-339

10. Lindberg S, Karlsson P, Arvidsson B, et al (1995) Cancer incidence after radiotherapy for skin haemangioma during infancy. Acta Oncol 34:735-740

11. Ron E, Lubin JH, Shore RE, et al (1995) Thyroid cancer after exposure to external radiation: a pooled analysis of seven studies. Radiat Res 141:259-277

12. Hildreth NG, Shore RE, Dvoretsky PM (1989) The risk of breast cancer after irradiation of the thymus in infancy. N Engl J Med 321:1281-1284

13. Lundell M, Mattsson A, Karlsson P, et al (1999) Breast cancer risk after radiotherapy in infancy: a pooled analysis of two Swedish cohorts of 17,202 infants. Radiat Res 151:626-632

14. Preston DL, Mattsson A, Holmberg E, et al (2002) Radiation effects on breast cancer risk: a pooled analysis of eight cohorts. Radiat Res 158:220-235

15. Ron E, Modan B, Boice JD Jr (1988) Mortality after radiotherapy for ringworm of the scalp. Am J Epidemiol 127:713-725

16. Lundell M, Holm LE (1996) Mortality from leukemia after irradiation in infancy for skin hemangioma. Radiat Res 145:595-601

17. Ron E, Modan B, Boice JD Jr, et al (1988) Tumors of the brain and nervous system after radiotherapy in childhood. N Engl J Med 319:1033-1039
18. Sadetzki S, Chetrit A, Freedman L, et al (2005) Long-term follow-up for brain tumor development after childhood exposure to ionizing radiation for tinea capitis. Radiat Res 163:424-432

19. Karlsson P, Holmberg E, Lundell M, et al (1998) Intracranial tumors after exposure to ionizing radiation during infancy: a pooled analysis of two Swedish cohorts of 28,008 infants with skin hemangioma. Radiat Res 150:357-364

20. Shore RE, Moseson M, Xue X, et al (2002) Skin cancer after X-ray treatment for scalp ringworm. Radiat Res 157:410-418

21. Ron E, Modan B, Preston D, et al (1991) Radiation-induced skin carcinomas of the head and neck. Radiat Res 125:318-325

22. Boice JD Jr, Monson RR (1977) Breast cancer in women after repeated fluoroscopic examinations of the chest. J Natl Cancer Inst 59:823-832

23. Howe GR, Miller AB, Sherman GJ (1982) Breast cancer mortality following fluoroscopic irradiation in a cohort of tuberculosis patients. Cancer Detect Prev 5:175-178

24. Howe GR, McLaughlin J (1996) Breast cancer mortality between 1950 and 1987 after exposure to fractionated moderate-dose-rate ionizing radiation in the Canadian fluoroscopy cohort study and a comparison with breast cancer mortality in the atomic bomb survivors study. Radiat Res 145:694-707

25. Miller AB, Howe GR, Sherman GJ, et al (1989) Mortality from breast cancer after irradiation during fluoroscopic examinations in patients being treated for tuberculosis. N Engl J Med 321:1285-1289

26. Morin Doody M, Lonstein JE, Stovall M, et al (2000) Breast cancer mortality after diagnostic radiography: findings from the U.S. Scoliosis Cohort Study. Spine 25:2052-2063

27. Shu XO, Gao YT, Brinton LA, et al (1988) A population-based case-control study of childhood leukemia in Shanghai. Cancer 62:635-644

28. Infante-Rivard C, Mathonnet G, Sinnett D (2000) Risk of childhood leukemia associated with diagnostic irradiation and polymorphisms in DNA repair genes. Environ Health Perspect 108:495-498

29. Shu XO, Potter JD, Linet MS, et al (2002) Diagnostic X-rays and ultrasound exposure and risk of childhood acute lymphoblastic leukemia by immunophenotype. Cancer Epidemiol Biomark Prev 11:177-185

30. Modan B, Keinan L, Blumstein T, et al (2000) Cancer following cardiac catheterization in childhood. Int J Epidemiol 29:424-428

31. Spengler RF, Cook DH, Clarke EA, et al (1983) Cancer mortality following cardiac catheterization: a preliminary follow-up study on 4,891 irradiated children. Pediatrics 71:235-239

32. McLaughlin JR, Kreiger N, Sloan MP, et al (1993) An historical cohort study of cardiac catheterization during childhood and the risk of cancer. Int J Epidemiol 22:584-591 